\title{
Does Fluoride Cause Corrosion of Titanium Dental Implants?
}

\author{
Barry M Fraser
}

\begin{abstract}
Aims: There is very little information known about the effects of fluoride on the corrosion of titanium dental implants. Corrosion of implants can lead to peri-implantitis and eventually implant failure. The aim of this study is to search and analyze the available literature to identify whether fluoride causes corrosion of titanium or Ti- $6 \mathrm{Al}-4 \mathrm{~V}$, two materials commonly used to construct dental implants.

Materials and methods: Three online databases were used to search for literature relating to this subject. These included Medline, Cumulative Index to Nursing and Allied Health Literature (CINAHL), and Dentistry and Oral Sciences. A scoping search was initially undertaken to identify potentially relevant literature. The studies were narrowed down by titles and abstract and then full-text review, based on predetermined inclusion/ exclusion criteria. Five studies were selected. The relevant information from the studies were extracted using a customized data extraction tool. The data were then analyzed allowing the conclusions to be drawn.

Results: Of the five studies included in this mini-systematic review, all concluded that fluoride does cause corrosion of dental implants, particularly, in the presence of an acidic $\mathrm{pH}$.

Conclusion: Consideration must be given when prescribing topical fluorides for patients with titanium dental implants. Corrosion can occur in the presence of high fluoride levels, particularly if the oral environment is acidic.

Keywords: Acids, Corrosion, Dental implants, Fluoride, Implants, Minisystematic review, Titanium.

International Journal of Oral Implantology and Clinical Research (2018): 10.5005/jp-journals-10012-1179
\end{abstract}

\section{INTRODUCTION}

Dental patients have become less accepting of edentulous spaces and are now keener than ever to replace missing teeth, with the restoration of esthetics and function being the main drivers for seeking prosthodontic rehabilitation. ${ }^{1}$ Dental implants are commonly used to replace missing teeth. ${ }^{2}$ Titanium has always been the material of choice for dental implants. It was considered due to its lightness and good mechanochemical properties. ${ }^{3}$ It was found to be the only biomaterial to osseointegrate ${ }^{4}$ and was assumed to have bioactive properties due to the formation of a hydrated oxide layer which could incorporate calcium and phosphorous. ${ }^{5}$ The high stability of titanium is created thanks to the formation of the titanium oxide $\left(\mathrm{TiO}_{2}\right)$ layer, which forms on the outer aspect of the implant. The stability of the implant can, however, be compromised if the $\mathrm{TiO}_{2}$ layer is lost and cannot reform. This then makes titanium as unstable as any other metal. ${ }^{6}$

Corrosion is the deterioration of a metal as a result of an electrochemical attack from the surrounding medium, which can lead to metal ion release. ${ }^{7}$ The metal ions which are released have a detrimental effect on the peri-implant tissues. ${ }^{8}$ Metal ions will cause the activation of inflammatory response cells, cytokines, and proinflammatory mediators and will result in an increase in osteoclastic activity. Products from the degradation of dental implants have cytotoxic (cell killing) and genotoxic (damaging to cells genetic material) potential for the tissues surrounding implant. ${ }^{9}$

Fluoride may contribute to the corrosion of dental implants. Fluoride has been used in dental hygiene products for many years. It is predominately used in the prevention of dental caries. Dentists will prescribe higher dosages for those who are at a higher risk of the disease. ${ }^{10}$

With the numbers of dental implants being placed increasing, and with the continued drive for the prevention of dental caries through the delivery of topical fluoride, it is important to explore whether corrosion of titanium dental implants can occur in the
Department of Restorative Dentistry, Glasgow Dental Hospital, Glasgow, UK

Corresponding Author: Barry M Fraser, Department of Restorative Dentistry, Glasgow Dental Hospital, Glasgow, UK, Phone: +44 1412119600, e-mail: barryfraser1@hotmail.com

How to cite this article: Fraser BM. Does Fluoride Cause Corrosion of Titanium Dental Implants? Int J Oral Implantol Clin Res 2018;9(1-3): 7-10.

Source of support: Nil

Conflict of interest: None

presence of topical fluoride. This mini-systematic review aimed to search the current literature for evidence that fluoride causes corrosion of titanium dental implants.

\section{Materials and Methods}

This minisystematic review followed multiple-ordered stages to help identify, critically appraise, and analyze the available body of evidence in this area of research. These stages included an extensive literature search, study selection based on predetermined inclusion/ exclusion criteria, data extraction, and data analysis. The literature search was conducted using three separate databases. The aim is to identify as many in vitro studies as possible addressing this same research question. Data analysis and interpretation were then conducted. All relevant information was extracted from the studies. The results of the studies were then analyzed in depth.

\section{Literature Search}

The literature search was conducted using three separate databases on the Elton B Stephens Company (EBSCO) platform. The databases used included Medline, Dentistry and Oral Sciences, and CINAHL.

The search for literature was undertaken using a combination of free text and indexed terms. 


\section{Inclusion and Exclusion Criteria}

The inclusion and exclusion criteria are included in Table 1 (see Appendix).

\section{Study Selection and Quality Assessment}

The identified studies were screened by title and abstract and any irrelevant studies removed. The remaining full texts were screened using the predetermined inclusion and exclusion criteria and only the most suitable studies retained. These studies were then screened for quality using a customized risk of bias (RoB) tool. This had to be created because no suitable RoB tools were identified after searching the literature for previously constructed tools. Its purpose was to provide an effective way to qualitative assess nonrandomized control trials which were then to be used in the systematic review. It would also ensure that the papers retrieved are nonbiased and conducted using a sound methodology. The studies were then grouped as "strong," "medium," or "weak" based on the score of the RoB tool. Only studies which were considered as "strong" were included in the review. Altogether, five studies were included in this review.

\section{Data Extraction}

Data were collected with the aid of a specifically designed "data extraction form." This tool streamlined the data extraction process by making it clearer and more concise and made the data extraction process reproducible.

The tool contained the following information:

- Reference-authors name, the title of the paper, and publication details

- Objective of the study

- Materials to be studied

- Intervention

- Analysis

- Outcome

\section{Data Analysis}

Narrative analysis of each study was undertaken, and similarities were identified. The conclusions drawn from the included studies were based on the similarities found in each individual study.

\section{Results}

A glossary of terms has been included at the end of this report.

Five studies were included in this minisystematic review and the findings from each study were as follows.

Boere et al. ${ }^{11}$-The authors tested samples of pure titanium electrochemically using a corrosion cell. Three experiments were conducted: experiment I-fluoride added to the test solution of sodium chloride $(\mathrm{NaCl})$ of $9.0 \mathrm{~g} \mathrm{~L}^{-1}$ immediately; experiment II-fluoride added to the same test solution after at 100 hours; experiment III-fluoride added to the same test solution after 3 weeks. This was conducted at $\mathrm{pH} 4$ using a hydrion buffer. The data were collected, and standard electrochemical measurements were obtained. These included corrosion potential $\left(E_{\text {corr }}\right)$ and polarization resistance $\left(R_{\mathrm{p}}\right)$.

Corrosion was identified graphically by a drop-in polarization resistance with an increasing concentration of fluoride and change in $E_{\text {corr }}$ from positive (+ve) to negative (-ve).

Experiment I pH 4: sodium fluoride (NaF) was added immediately. There was a limiting value for $\mathrm{NaF}$ concentration whereby concentrations lower than this would not affect $E_{\text {corr }}$ or $R_{\mathrm{p}}$ after this limit was reached, the corrosive process occurred.

Experiment II pH 4: NaF added at 100 hours. The starting value for $R_{\mathrm{p}}$ was higher and the influence of HF was detected with lower concentrations of fluoride. This occurred because the longer that titanium was placed in solution, the thicker the protective oxide layer became (resulting in a higher starting value for $R_{\mathrm{p}}$ ). With the continual addition of $\mathrm{HF}$, the oxide layer became depleted resulting in a steep fall in corrosion potential and polarization.

Experiment III pH 4: NaF added after 3 weeks. The trend was similar to experiments I and II.

The data show that even at low concentrations, when NaF is added at a low $\mathrm{pH}$, titanium attack begins.

In the experiments conducted at $\mathrm{pH} 7$, results show that the polarization resistance is relatively stable and consistent. The $R_{\mathrm{p}}$ and $E_{\text {corr }}$ are maintained due to a lack of acidic hydrogen ions. The hydrogen ions will bind to the passive oxide layer on the sample surface and begin degrading the surface.

Joska et al. ${ }^{12}$ - The authors tested samples of pure titanium in an electrochemical cell. The samples were tested in multiple different test solutions: $\mathrm{NaCl}(9 \mathrm{~g} / \mathrm{L})$-abbreviation PS-n.a.; $\mathrm{NaCl}(9 \mathrm{~g} / \mathrm{L})$ + 5,000 ppm-abbreviation PS-n.a./5,000; NaCl (9 g/L) + buffer solution (to change pH to 5.8) - abbreviation PS-5.8; $\mathrm{NaCl}(9 \mathrm{~g} / \mathrm{L})+$ $5,000 \mathrm{ppm}+$ buffer solution (to change $\mathrm{pH}$ to 5.8 ) - abbreviation PS-5.8/5,000; $\mathrm{NaCl}(9 \mathrm{~g} / \mathrm{L})+$ buffer solution (to change $\mathrm{pH}$ to 4.2$)$ abbreviation PS-4; $\mathrm{NaCl}(9 \mathrm{~g} / \mathrm{L})+5,000 \mathrm{ppm}+$ buffer solution (to change $\mathrm{pH}$ to 4.2) -abbreviation PS-4.2/5,000; model saliva-1.5 $\mathrm{g} / \mathrm{L} \mathrm{KCl}, 0.5 \mathrm{~g} / \mathrm{L} \mathrm{NaH}_{2} \mathrm{PO}_{4} \cdot \mathrm{H}_{2} \mathrm{O}, 1.5 \mathrm{~g} / \mathrm{L} \mathrm{NaHCO}_{3}, 0.5 \mathrm{~g} / \mathrm{L} \mathrm{KSCN} ; 0.9 \mathrm{~g} / \mathrm{L}$ lactic acid-abbreviation MS (control solution).

The data were presented using potentiodynamic (polarization) curves. From this, current density $\left(\mathrm{A} / \mathrm{cm}^{2}\right)$ and corrosion potential $(E)$ were measured. The samples were placed in the test solutions. Current density increased, and corrosion potential became more negative when fluoride was added.

The corrosion potential and the polarization resistance were then measured again the time. The graphs showed that in both PS n.a./5,000 and PS 5.8/5,000, the corrosion potential was negative suggesting that corrosion was occurring. After placement into the model saliva, this began to reverse until the corrosion potential returned positive and the polarization resistance also began to increase which suggested that the passive $\mathrm{TiO}_{2}$ layer was beginning to reform. In the PS 4.2/5,000 test solution, the corrosion potential did not become positive again suggesting that electrons were still present in titanium. Polarization resistance also stayed very low suggesting no repassivation. The corrosion process did not stop in this test.

The impact on the passive $\mathrm{TiO}_{2}$ layer was the greatest with an acidic $\mathrm{pH}$. A drop in the polarization resistance with all PS n.a./5,000, PS 5.8/5,000, and PS4.2/5,000 would suggest that the $\mathrm{TiO}_{2}$ layer is deteriorating.

Surface analysis-impedance spectra-taken for the titanium sample in PS 4.2/5,000 solution. This confirmed the presence of a layer of corrosion products after exposure to the test solution. $\mathrm{X}$-ray photoelectron spectroscopy was run on this and showed layers of titanium, potassium, fluoride, and oxygen elements on the surface of the sample.

These findings conclude that prolonged exposure to fluoride will lead to corrosion of titanium, particularly if the $\mathrm{pH}$ is low.

Nakagawa et al. ${ }^{13}$ - Samples of commercially pure titanium tested in an electrochemical cell. The data were presented 
using polarization curves. From this, the corrosion potential was measured.

The anodic polarization curves were first measured in artificial saliva $\left(\mathrm{NaCl} 0.4 \mathrm{~g}, \mathrm{KCl} 0.4 \mathrm{~g}, \mathrm{CaCl}_{2} \cdot 2 \mathrm{H}_{2} \mathrm{O} 0.795 \mathrm{~g}, \mathrm{NaH}_{2} \mathrm{PO}_{4} \cdot 2 \mathrm{H}_{2} \mathrm{O} 0.78 \mathrm{~g}\right.$, $\mathrm{Na}_{2} \mathrm{~S}_{9} \cdot \mathrm{H}_{2} \mathrm{O} 0.005 \mathrm{~g}, \mathrm{NH}_{2} \mathrm{CONH}_{2} 1.0 \mathrm{~g}$, distilled water $1,000 \mathrm{~mL}$ ) which would act as a control and $0.1 \% \mathrm{NaF}$ solution at pHs 7.1 and 4.0.

Similarities were seen in the polarization curves for artificial saliva and $0.1 \% \mathrm{NaF}$ solution at $\mathrm{pH}$ 7.1. This would suggest that no corrosion is occurring. When assessing the polarization curve for $0.1 \% \mathrm{NaF}$ at $\mathrm{pH} 4.0$, the corrosion potential dropped suggesting an increase in the number of free electrons in the sample. The current density also increased which suggests a change to the surface characteristics of the sample metal. The sample then began to passivate.

The same tests were then re-run with an increased fluoride concentration, this time $0.5 \%$ with varying $\mathrm{pH}$ levels. The corrosion resistance was lost at $0.1 \% \mathrm{NaF}(452.4 \mathrm{ppm})$ at $\mathrm{pH} 4.2$ and at $0.5 \%$ $\mathrm{NaF}$ at $\mathrm{pH}$ 5.4.

Limit values were measured from the polarization tests and the immersion tests. They showed that at 100 ppm, corrosion would occur at approximately $\mathrm{pH} 3$, at 1,000 ppm approximately $\mathrm{pH} 5$, and at 10,000 ppm approximately $\mathrm{pH} 6.5$.

\section{Surface Analysis}

Analysis of dissolved titanium and fluoride-The concentration of dissolved titanium in solution was measured in $\mu \mathrm{g} / \mathrm{cm}^{2}$ and was measured in solutions of 0.05 and $0.1 \% \mathrm{NaF}$ at varying $\mathrm{pHs}$.

The solutions were tested immediately once anodic polarization tests were conducted after 24 hours in solution. With $0.05 \% \mathrm{NaF}$ solution at $\mathrm{pH} 3.5$, over $400 \mu \mathrm{g} / \mathrm{cm}^{2}$ was identified in the solution. This increased to approximately $1,750 \mu \mathrm{g} / \mathrm{cm}^{2}$ after 24 hours. At $0.1 \% \mathrm{NaF}$, over $1,000 \mu \mathrm{g} / \mathrm{cm}^{2}$ was identified in the solution and this increased to around $2,700 \mu \mathrm{g} / \mathrm{cm}^{2}$ after 24 hours. Dissolution was identified at all pHs measured in both 0.05 and $0.1 \%$ solutions.

Milošev et al. ${ }^{14}$-Samples of pure titanium and Ti-6Al-4V tested in an electrochemical cell. Data were extracted and polarization curves were plotted allowing corrosion potential, $E_{\text {corr }}$ and current density, $j_{\text {corr }}$ to be measured. The results are displayed in Table 2 (see Appendix).

In artificial saliva, $E_{\text {corr }}$ for both $\mathrm{Ti}$ and $\mathrm{Ti}-6 \mathrm{Al}-4 \mathrm{~V}$ were negative in value (more so, for Ti-6Al-4V) but returning to positive. This suggests that samples were passivating and becoming more stable (most likely as a result of an increase in the thickness of the $\mathrm{TiO}_{2}$ layer). In artificial saliva, Ti was found to be very stable, whereas $\mathrm{Ti}-6 \mathrm{Al}-4 \mathrm{~V}$ was less protected to localized corrosion.

The addition of $\mathrm{NaF}$ led to significant changes in the polarization curves. For both $\mathrm{Ti}$ and $\mathrm{Ti}-6 \mathrm{Al}-4 \mathrm{~V}$, the $E_{\text {corr }}$ value became significantly more negative indicating that a dissolution process is occurring through a reduction and oxidation-type reaction. Free electrons explain the negative change. The current density is also increased with the addition of fluoride.

These results would indicate that corrosion resistance is reduced by the addition of fluoride.

Immersion tests-Samples were immersed in artificial saliva for 32 days with and without the addition of $\mathrm{NaF}$. The concentration of dissolved titanium ions in solution was measured. The amount of dissolved titanium from the $\mathrm{Ti}$ and $\mathrm{Ti}-6 \mathrm{Al}-4 \mathrm{~V}$ samples was similar in artificial saliva. This was $10 \mu \mathrm{g} / \mathrm{L}$. This value indicates low levels of corrosion. After the addition of $\mathrm{NaF}$, this figure vastly increased to around $45,000 \mu \mathrm{g} / \mathrm{L}$ for Ti-6Al-4V and $68,000 \mu \mathrm{g} / \mathrm{L}$ for Ti. Average values and standard deviations were calculated. This significant increase confirms the corrosion of the samples.
Schiff et al. ${ }^{15}$-Samples of titanium and Ti-6Al-4V tested in an electrochemical cell. Polarization curves were plotted, and corrosion potential, polarization resistance, and current density were measured after immersing samples for 24 hours.

The corrosion potential was initially measured in the Fusyama Mayer artificial saliva $\left(\mathrm{KCl}(0.4 \mathrm{~g} / \mathrm{L}), \mathrm{NaCl}(0.4 \mathrm{~g} / \mathrm{L}), \mathrm{CaCl}_{2} \cdot 2 \mathrm{H}_{2} \mathrm{O}\right.$ (0.906 g/L), $\mathrm{NaH}_{2} \mathrm{PO}_{4} \cdot 2 \mathrm{H}_{2} \mathrm{O}(0.690 \mathrm{~g} / \mathrm{L}), \mathrm{Na}_{2} \mathrm{~S}_{9} \cdot \mathrm{H}_{2} \mathrm{O}(0.005 \mathrm{~g} / \mathrm{L})$, urea ( $1 \mathrm{~g} / \mathrm{L}) ; \mathrm{pH}$ of artificial saliva is 5.3). The titanium sample was stabilized at $25 \mathrm{mV} / \mathrm{SCE}$. This suggests repassivation of the metal. This then changed to $-80 \mathrm{mV} / \mathrm{SCE}$ in the acidified saliva (Fusyama Mayer artificial saliva $\mathrm{pH}$ 2.5). This is not significantly different from the artificial saliva and the corrosion potential is only slightly negative suggesting that the passive layer is not degraded. In the fluoridated saliva (Fusyama Mayer artificial saliva with 1,000 ppm fluoride), the potential dropped to $-300 \mathrm{mV} / \mathrm{SCE}$. This would indicate that the protective passive layer had been changed and that corrosion was occurring. With the acidified and fluoridated saliva (Fusyama Mayer artificial saliva pH 2.5 with 1,000 ppm fluoride), the potential dropped significantly to $-850 \mathrm{mV} / \mathrm{SCE}$. This again shows a significant change to the passive layer leading to corrosion of the metal.

The Ti-6Al-4V also showed a similar pattern. This changed from $0,-50,-370,-800 \mathrm{mV} / \mathrm{SCE}$ in the Fusyama Mayer artificial saliva, acidified saliva, fluoridated saliva, and fluoridated acidified saliva, respectively.

The results for both corrosion potential and current density would suggest that corrosion is caused by the presence of fluoride and acidified fluoride solutions.

\section{Discussion}

All of the studies which were analyzed showed that fluoride did cause corrosion of titanium and Ti-6Al-4V alloys. The study by Broere et al. ${ }^{11}$ proved that there was a minimum fluoride concentration needed to cause corrosion at a neutral $\mathrm{pH}$, below which no effects were seen. However, at a low $\mathrm{pH}$, the concentration of fluoride needed to cause corrosion was low and this was due to the effects of hydrogen fluoride on the passive $\mathrm{TiO}_{2}$ layer found on the metal/ alloy surface. The study found that the concentration of fluoride in the mouth is $0.2-1.5 \mathrm{mmol}$ after the use of fluoride-containing toothpaste. After the use of fluoride rinses, the concentration can increase to 1.2-2.9 mmol. When fluoride gels are used, the concentration can be as high as $7 \mathrm{mmol}$. These concentrations are well beyond what is capable of causing corrosion.

Joska et al. ${ }^{12}$ also concluded that fluoride caused corrosion of pure titanium. This was found to be more profound when the $\mathrm{pH}$ was more acidic. The study also examined the surface of the titanium after exposure to the test solutions and this showed a clear build-up of corrosion products. It is these corrosion products which will begin to cause peri-implant inflammation and potentially implant failure.

The study by Nakagawa et al. ${ }^{13}$ measured limit values from the polarization tests and the immersion tests and showed that at $100 \mathrm{ppm}$, corrosion would occur at approximately $\mathrm{pH} 3$, at 1,000 ppm approximately $\mathrm{pH}$ 5, and at 10,000 ppm approximately $\mathrm{pH} 6.5$. These findings are very significant as some prescribed toothpastes can have a concentration as high as 5,000 ppm fluoride and topical fluoride varnishes can be as high as 22,600 ppm. The findings are significant, particularly if the $\mathrm{pH}$ is reduced such as in high plaque areas.

Milosev et al. ${ }^{14}$ also provided conclusive data on the effects of fluoride and the corrosion of pure titanium and $\mathrm{Ti}-6 \mathrm{Al}-4 \mathrm{~V}$. 
Both the electrochemical tests and the visual tests confirmed that corrosion of the samples occurred in the presence of fluoride and with an adjusted $\mathrm{pH}$ of 5.3. The $\mathrm{pH}$ remained constant throughout the experiments with the only fluoride being adjusted.

The study by Schiff et al. ${ }^{15}$ again concluded through electrochemical testing that fluoride has a significant effect on the corrosive properties of pure titanium and Ti-6Al-4V. The effects were more significant in the presence of low $\mathrm{pH}$.

\section{Conclusion}

The studies have shown that high concentrations of fluoride will indeed cause corrosion of dental implants made from pure titanium or $\mathrm{Ti}-6 \mathrm{Al}-4 \mathrm{~V}$. The studies also showed that low concentrations of fluoride will cause corrosion in the presence of an acidic $\mathrm{pH}$, a situation which can commonly occur in the mouth. The concentration of fluoride dentifrices must be considered in dental implant patients to ensure that peri-implant tissues are not compromised due to the release of corrosive products from titanium dental implants.

\section{Clinical Significance}

The concentrations of fluoride prescription must be considered for patients with dental implants. Prescriptions of a high level of fluoride may have a negative impact on the peri-implant health due to the formation of corrosion products.

\section{References}

1. Al-Quran FA, Al-Ghalayini RF, et al. Single-tooth replacement: factors affecting different prosthetic treatment modalities. BMC Oral Health 2011 Dec 21;11:34. DOI: 10.1186/1472-6831-11-34.

2. Gaviria L, Salcido JP, et al. Current trends in dental implants. J Korean Assoc Oral Maxillofac Surg 2014 Apr;40(2):50-60. DOI: 10.5125/ jkaoms.2014.40.2.50
3. Oldani C, Dominguez A. Titanium as a Biomaterial for Implants. In: Fokter S. ed. Recent Advances in Arthroplasty 2012. ISBN: 978-953307-990-5.

4. Van Noort R. Titanium: The implant material of today. J Mater Sci 1987;22:3801-3811. DOI: 10.1007/BF01133326.

5. Li P, Kangasniemi I, et al. Hydroxyapatite Induction by a Gel-Derived Titania on a Titanium Substrate. J Ceram Soc 1994;77(5):1307-1312. DOI: 10.1111/j.1151-2916.1994.tb05407.x.

6. Chaturvedi TP. An overview of the corrosion aspect of dental implants (titanium and its alloys). Indian J Dent Res 2009 Jan;20(1):91-98. DOI: 10.4103/0970-9290.49068.

7. Kinga T. Surface Aspects of Titanium Dental Implants, Biotechnology-Molecular Studies and Novel Applications for Improved Quality of Human Life, Sammour R. ed.; 2012. ISBN: 978953-51-0151-2.

8. Noronha Oliveira M, Schunemann WVH, et al. Can degradation products released from dental implants affect peri-implant tissues? J Periodontal Res 2018 Feb;53(1):1-11. DOI: 10.1111/jre.12479.

9. Anwar EM, Kheiralla LS, et al. Effect of fluoride on the corrosion behavior of $\mathrm{Ti}$ and Ti6Al4V dental implants coupled with different superstructures. J Oral Implantol 2011 Jun;37(3):309-317. DOI: 10.1563/ AAID-JOI-D-09-00084.

10. Muñoz HE, Standley E. Current Fluoride Modalities for Reduction of Dental Caries. RDH 2013 Feb;33(2):63-69.

11. Boere $G$. Influence of fluoride on titanium in an acidic environment measured by polarization resistance technique. J Appl Biomater 1995;6(4):283-288. DOI: 10.1002/jab.770060409.

12. Joska L, Fojt J. Corrosion behaviour of titanium after short-term exposure to an acidic environment containing fluoride ions. J Mater Sci Mater Med 2010 Feb;21(2):481-488. DOI: 10.1007/s10856-009-3930-y.

13. Nakagawa $M$, Matsuya $S$, et al. Effect of fluoride concentration and $\mathrm{pH}$ on corrosion behavior of titanium for dental use. J Dent Res 1999 Sep; 78(9):1568-1572. DOI: 10.1177/00220345990780091201.

14. Milošev I, Kapun B, et al. The effect of fluoride ions on the corrosion behaviour of Ti metal, and Ti6-AI-7Nb and Ti-6Al-4V alloys in artificial saliva. Acta Chim Slov 2013;60(3):543-555.

15. Schiff N, Grosgogeat B, et al. Influence of fluoride content and pH on the corrosion resistance of titanium and its alloys. Biomaterials 2002 May;23(9):1995-2002. DOI: 10.1016/S0142-9612(01)00328-3.

\section{Appendix}

Table 1: Inclusion and exclusion criteria

\begin{tabular}{|c|c|c|}
\hline Category & Inclusion & Exclusion \\
\hline Language & English & Non-English \\
\hline Date of publication & No limit & No limit \\
\hline Population & $\begin{array}{ll}\text { - } & \text { Dental implants } \\
\text { - } & \text { Pure titanium } \\
\text { - } & \text { Ti-6Al-4V }\end{array}$ & $\begin{array}{l}\text { - Orthodontic implants } \\
\text { - Mini implants } \\
\text { - Zirconia implants } \\
\text { - Experimental titanium alloys }\end{array}$ \\
\hline Intervention & $\begin{array}{l}\text { - Topical fluoride application } \\
\text { - Studies which assess fluoride application at different pH } \\
\text { - Studies which examine corrosion in artificial saliva } \\
\text { - Studies which examine corrosion in saliva substitute }\end{array}$ & $\begin{array}{l}\text { - Studies which examine the effects of } \\
\text { mechanical trauma on corrosion } \\
\text { - Studies which artificially change the } \\
\text { surface characteristics of the metal prior } \\
\text { to testing for corrosion }\end{array}$ \\
\hline Study design & - In vitro & - In vivo \\
\hline Other & - Full texts available & $\begin{array}{l}\text { - Texts without full access or texts with } \\
\text { restricted access }\end{array}$ \\
\hline
\end{tabular}

Table 2: Results from paper by Milosev et al.

\begin{tabular}{lllll}
\hline & & & Artificial saliva + & $\begin{array}{l}\text { Artificial saliva }+ \\
0.25 \% \mathrm{NaF}\end{array}$ \\
\cline { 2 - 5 } Material & Artificial saliva & Artificial saliva & $0.25 \% \mathrm{NaF}$ & $j_{\text {corr }} / \mathrm{V}$ \\
\hline $\mathrm{Ei}$ & $E_{\text {corr }} / \mathrm{V}$ & $j_{\text {corr }} / \mathrm{V}$ & $E_{\text {corr }} / \mathrm{V}$ & $1.2 \times 10^{-8}$ \\
$\mathrm{Ti}-6 \mathrm{Al}-4 \mathrm{~V}$ & -0.40 & $5.0 \times 10^{-8}$ & -0.62 & $4.0 \times 10^{-6}$ \\
\hline
\end{tabular}

